Original Research

\title{
Potential Loss among Infant Feeding Options
}

\author{
Azniah Syam¹, Musni Musni², Andi Nurzakiah Amin ${ }^{3}$ and Imelda Iskandar ${ }^{4}$ \\ ${ }^{1}$ College of Health Sciences General Nani Hasanuddin, Indonesia \\ 2 Akademi Kebidanan Batari Toja Watampone, Indonesia \\ 3 Universitas Cendrawasih Papua, Indonesia \\ ${ }^{4}$ Akademi Kebidanan Yapma Makassar, Indonesia
}

\begin{abstract}
Introduction: The conceptual relationship between economics and breastfeeding is still mathematically invaluable, while the family's economic burden increases along with babies born. Indicating potential loss when a family chooses other than breastmilk is a progressive way to manage campaign messages about exclusive breastmilk and prolonged breastfeeding. Descriptive studies are needed to magnify all of these indicators and transform them into measuring instruments generalized to assess family expenditures related to infant feeding.
\end{abstract}

Methods: This study uses a quantitative descriptive design, questionnaire draft upon qualitative open questions containing all micro indicators impacted financially during the baby's first year. Data collection was carried out in Makassar based on telephone surveys with 330 preliminary samples. After structural analysis and data reduction, the expenditure indicators were divided into medical and non-medical expenses.

Results: The study show there is a difference in the average amount of family expenses of those who provide formula milk compared to breastmilk. This outcome is 21.1 times higher in non-medical components and 2.5 times higher in the medical component. One of the highest contributions in medical expenses is the cost of a recurrent visit to a pediatrician due to a history of illness such as allergies, respiratory infections, and diarrhea.

Conclusion: This empirical fact stated the strong affirmation of how families should consider wisely to choose the best feeding pattern for babies aged 0 12 months.

\section{ARTICLE HISTORY}

Received: November 17, 2020

Accepted: March 17, 2021

\section{KEYWORDS}

economic loss; medical expenses; non-medical expenses; exclusive breastfeeding; formula feeding

\section{CONTACT}

Azniah Syam

$\bowtie$ azniahsyam@gmail.com

$\equiv$ College of Health Sciences General Nani Hasanuddin, Indonesia

Cite this as: Syam, A., Musni, M., Amin, A. N., \& Iskandar, I. (2021). Potential Loss among Infant Feeding Options. Jurnal Ners, 16(1). 74-80. doi:http://dx.doi.org/10.20473/jn.v16i1.23285

\section{INTRODUCTION}

Various factor influence the mother's decision to meet the nutritional needs of infants aged 0-12 month (Brown et al., 2014a; Ulak et al., 2012). Despite the undeniable fact that breastmilk is the best choice (Eidelman \& Schanler, 2012; Kent, 2007) especially for ages 0-6 months (Chowdhury et al., 2015), there are still many families who fail to fulfill this option (Bascom \& Napolitano, 2016; Cato et al., 2017; Ogbo et al., 2017). Termination of breastmilk encourages them to choose formula milk as a substitute. Some of the factors that caused families to choose this option reported from various surveys were low milk production, breast milk did not come out on the first postpartum day, problems with nipples (pain, blisters, sores), breasts (swelling, mastitis), fatigue, work (Brown et al., 2014b; Dennis et al., 2014; Olang et al., 2012; Puapornpong et al., 2017). The reason for working is a trigger for the high use of formula milk (Buccini et al., 2014; Thomas-Jackson et al., 2016). But many mothers who do not work choose formula milk due to several physiological problems in the nipples and breasts (Puapornpong et al., 2017). This nipple problem and fatigue can be overcome with proper breastfeeding techniques by providing the best support system in the mother's environment, such as sharing the caregiver's duties in caring for children (Aubel \& Alvarez, 2011; Houghtaling et al., 2018), maintaining hormonal and mental balance to avoid 
anxiety (Akman et al., 2008; Douglas \& Hiscock, 2010; Nicklas et al., 2013; Susiloretni et al., 2013; Xu et al., 2014). Sometimes there are reasons that the baby is not satisfied with breast milk, so that they cry too much and the mother becomes frustrated to calm them down (Douglas \& Hiscock, 2010; Richter \& Reck, 2013). Again, this reason can be overcome by increasing the closeness of communication with the fetus during pregnancy through hypnobirthing and initiating early breastfeeding in the first hour of birth to stimulate suction and skin to skin contact (Creedy et al., 2008; Phillips-Moore, 2012).

Although the campaign for milk is intense, especially in developing countries, formula milk companies are ever more creative in marketing their products (Abrahams, 2012; WHO, 2011). They even target gaps in several national policies regulating breastfeeding for babies (Better Work Indonesia, 2004; Gupta et al., 2013). In Indonesia, even though the policy on breastmilk already exists, the achievement rate of giving exclusive breastmilk is still far from the SDG 2030 target (National Population and Family Planning Board (BKKBN), Statistics Indonesia (BPS), Ministry of Health (Kemenkes), 2018). Negative values seem to be normalized by formula milk producers through extraordinary advertisements, causing overestimation, such as completely nutritious food, smarter, stronger, happier babies and so on. Although buying formula milk means more expense, parents think this choice is better quality.

Indications of over expenditure in milk purchasing not only have an impact on higher expenditure, but also have an economic impact in the medium and long term. World Breastfeeding Week 2018 reported that breastfeeding can prevent malnutrition in all forms, ensure food security even in times of crisis, and break the chain of poverty in the long term. Despite the relatively high global initiation rate, only $40 \%$ of all infants under 6 months of age are exclusively breastfed and $45 \%$ continue to breastfeed until 24 months of age. In addition, there are large variations in state and country breastfeeding rates. Increasing optimal breastfeeding can prevent more than 823,000 children and 20,000 maternal deaths each year. Not breastfeeding is associated with lower intelligence and results in an estimated $\$ 302$ billion in economic losses each year.

However, this figure is just a number if there are no stressor indicators that provoke mothers and families being wiser in choosing formula feeding. Therefore, it is necessary to explore what disadvantages are experienced by families based on their feeding choices for babies.

\section{MATERIALS AND METHODS}

This research is a preliminary study, through a quantitative exploratory approach and aims to openly identify indicators related to all affected aspects of the choice of feeding patterns for infants aged 0-12 months. This research was carried out during the
January-July 2019 period, in one of the primary healthcare areas in Makassar City which has a moderate density level, various socio demography varieties, and the lowest achievement rate of exclusive breastfeeding in 2018. Determination of research subjects using purposive sampling technique was as many as 330 mothers who were surveyed by telephone. All research subjects were selected based on criteria, having babies aged 0-12 months, willing to be contacted via mobile phone several times according to data collection needs, and willing to be visited at home as one aspect of verifying the validity of the data provided.

The design of measuring instruments was in the form of a questionnaire with open questions from information about the mother's sociodemographic characteristics, the method of feeding the baby, the reasons for choosing this method, the daily consumption of formula milk products, the use of accompanying tools and materials such as bottled water, pacifiers, baby diapers to history of disease and hospitalization that the baby has had in the last three months. All semi-qualitative instruments will be coded and classified quantitatively so that they can be objectively calculated and analyzed. Descriptive data analysis is entirely presented in the form of comparison tables between groups, and the final hypothesis of the study, namely infants fed formula milk has a much greater loss effect than exclusive breastfeeding, which was tested using the Independent T test.

\section{RESULTS}

Based on the survey data, after going through the data quantification, they were grouped into two major items, namely medical complaints and non-medical expenses related to the feeding patterns of infants. Non-medical expenses are the accumulated increase in family spending including accessories for baby needs, and the financial needs of purchasing breastmilk replacement products. Medical expenses in the form of health impacts arising from the choice of feeding include health problems experienced by the baby during the last three months.

Table 1 shows that, out of 330, mothers are generally in the reproductive age of 20-35 years, with almost a quarter of the percentage of married young people ( $<20$ years). Generally, mothers have primary to secondary education, the percentage of housewives is more than half of the subjects, with a small percentage of husbands who do not work. Unemployment will aggravate the situation for families to meet the needs of newborns, with data on the percentage of income below 3 million more than half. Most of them had more than two children, with babies under six months exceeding two thirds of the number of subjects; this means that the infants studied were still in the phase of exclusive breastfeeding.

As much as $86.97 \%$ of families used disposable diapers, babies who had experienced illness and 
Table 1. Subject Characteristic $(n=330)$

\begin{tabular}{|c|c|c|}
\hline Characteristic & $\mathbf{f}$ & $\%$ \\
\hline \multicolumn{3}{|l|}{ Mother's Age } \\
\hline$<20$ years & 47 & 14.24 \\
\hline 20-35 years & 239 & 72.42 \\
\hline$>35$ years & 44 & 13.34 \\
\hline \multicolumn{3}{|l|}{ Mother's Marital Age } \\
\hline$<20$ years & 97 & 29.39 \\
\hline$\geq 20$ years & 233 & 70.61 \\
\hline \multicolumn{3}{|l|}{ Mother's Education } \\
\hline Basic & 82 & 24.84 \\
\hline Middle & 131 & 39.70 \\
\hline High & 55 & 16.67 \\
\hline Graduated & 62 & 18.79 \\
\hline \multicolumn{3}{|l|}{ Working profile } \\
\hline Working Mothers & 159 & 48.18 \\
\hline Housewife & 171 & 51.82 \\
\hline \multicolumn{3}{|l|}{ Working profile } \\
\hline Working Husband & 301 & 91.22 \\
\hline Unemployed Husband & 29 & 8.78 \\
\hline \multicolumn{3}{|l|}{ Parity } \\
\hline Primipara & 106 & 32.12 \\
\hline Multiparous & 224 & 67.89 \\
\hline \multicolumn{3}{|l|}{ Babies' Age } \\
\hline$<6$ month & 227 & 68.79 \\
\hline$\geq 6$ month & 103 & 31.21 \\
\hline \multicolumn{3}{|l|}{ Amount of Income } \\
\hline$<$ IDR 3,000,000,- & 177 & 53.64 \\
\hline$\geq$ IDR 3,000,000,- & 153 & 46.36 \\
\hline \multicolumn{3}{|l|}{ Disposable Diaper Used } \\
\hline Yes & 287 & 86.97 \\
\hline No & 43 & 13.03 \\
\hline \multicolumn{3}{|c|}{ Outpatient Period In Last One Year } \\
\hline Yes & 279 & 84.55 \\
\hline No & 51 & 15.45 \\
\hline \multicolumn{3}{|l|}{ Hospitalization Period in Last One } \\
\hline Year & 97 & 29.39 \\
\hline Yes & 240 & 72.71 \\
\hline \multicolumn{3}{|l|}{ No } \\
\hline \multicolumn{3}{|l|}{ Healthcare Preference } \\
\hline Primary Healthcare Clinic & 208 & 63.03 \\
\hline Pediatrician & 122 & 36.97 \\
\hline \multicolumn{3}{|l|}{ Health Insurance Belongings } \\
\hline Indonesian Nationals Health & 72 & 21.82 \\
\hline Insurance (BPJS) & 62 & 18.78 \\
\hline Indonesian Health Care & 11 & 3.33 \\
\hline Beneficiary (BPJS-KIS) & 32 & 9.67 \\
\hline \multicolumn{3}{|l|}{ Private Insurance } \\
\hline \multicolumn{3}{|l|}{ None } \\
\hline \multicolumn{3}{|l|}{ Feeding Option } \\
\hline Exclusive Breastfeeding & 165 & 50.0 \\
\hline Formula Feed & 165 & 50.0 \\
\hline
\end{tabular}

outpatient care were $88.55 \%$, hospitalization was $29.39 \%$ in the last one year. Generally, families prefer service facilities from primary healthcare clinics, as many as $21.82 \%$ are participants of national insurance, $18.78 \%$ are beneficiaries, a small proportion $(3.33 \%)$ have private insurance which is a facility from the workplace, and $9.67 \%$ of families do not have health insurance. This will be burdensome for the family's economic condition when there is an unpredictable risk of disease.
Table 2 shows the pattern of formula feeding with several related aspects. The use of formula milk with paper packaging was $84.8 \%$. Many of the reasons cited for choosing a particular brand of formula are because it is suitable for babies; most families who choose this diet prepare a special allocation budget. Some of the accompanying accessories, such as the use of teat media, periodic pacifier changes and the use of bottled water, contribute to formula feeding. This means that choosing formula will add some additional expense items and maintenance of the drinking medium. Also, the resulting effect in the form of waste adds to the environmental burden.

Based on the accumulated results of medical and non-medical expenditures, it can be concluded that the selection of formula milk clearly increases household routine expenditures, because formula milk requires media and materials for manufacture. This study also found empirically the increase in household spending from the medical aspect of formula milk groups. In other words, formula milk has a direct or indirect impact on the health status of the baby. Statistical test in both groups showed significant results.

Based on Table 4, it is shown that the frequency of occurrence of symptoms of allergies, asthma, and dengue fever is more experienced by infants who receive formula milk. Meanwhile, influenza symptoms were equally experienced by the two groups. The frequency of healthy babies was also seen to be higher in the breastfeeding group.

of the many cases of allergic symptoms, asthma, and flu symptoms, the percentage of babies who had to be hospitalized was higher in the formula milk group. Meanwhile, all cases of dengue fever received inpatient treatment. The identification of health problems in this study was validated by re-verifying the data on patient visits to health facilities mentioned by the mother when experiencing illness events. The identified diagnosis is based on the medical record that is written on the patient's visit report.

\section{DISCUSSION}

This study aims to determine and measure the adverse effects of feeding between infants who are exclusively breastfed and formula milk. Several measures were collected regarding the primary needs of infants under one year of age. The gauge identified is the effect of expenditure on food-related needs. The data collected from periodic telephone surveys are then divided into non-health expenditures and health-related expenditures. In the breastfeeding group, the number of non-medical routine expenditures increased from the use of disposable diapers, while, in the formula milk group, nonmedical routine expenditures were added with milk, pacifiers, bottled water, and disposable diapers. A must have extra item to this expense formula is sure to cause the family to spend more money (Stuebe et al., 2017). 
Table 2. Formula Feeding Pattern (n=165)

\begin{tabular}{|c|c|c|}
\hline Formula Feeding Pattern & $\mathbf{n}$ & $\%$ \\
\hline \multicolumn{3}{|l|}{ Formula Milk Packaging: } \\
\hline Cans & 25 & 15.2 \\
\hline Paper Box & 140 & 84.8 \\
\hline \multicolumn{3}{|l|}{ Reason for Formula Milk Feeding Choice: } \\
\hline Suitable for babies & 123 & 74.5 \\
\hline Complete nutrition & 38 & 23.0 \\
\hline Suggested by healthcare nurse/midwife & 4 & 2.5 \\
\hline \multicolumn{3}{|l|}{ Financial Specific Allocation for Formula Milk: } \\
\hline Prepared & 106 & 67.9 \\
\hline Unprepared & 50 & 32.1 \\
\hline \multicolumn{3}{|l|}{ Formula Feeding Equipment: } \\
\hline Pacifier & 154 & 98.7 \\
\hline Other & 2 & 1.3 \\
\hline \multicolumn{3}{|l|}{ Pacifier Changed Frequency: } \\
\hline Regular (every 3 months) & 117 & 75.6 \\
\hline Irregular & 37 & 24.4 \\
\hline \multicolumn{3}{|l|}{ Water Consumption: } \\
\hline Bottled Water & 66 & 42.3 \\
\hline Boiled Water & 90 & 57.7 \\
\hline
\end{tabular}

Table 3. Comparison of Average Family Losses based on Accumulated Non-Medical Economic Impacts (in Indonesian Rupiah)

\begin{tabular}{lccc}
\hline \multicolumn{1}{c}{ Family Expenditure } & Breastfeeding & Formula Feeding & $*$ p \\
\hline Non-Medical Expenditure & $421,450.0 \pm 273,098.6$ & $8,873,569.3 \pm 4,012,883.9$ & $<0.001$ \\
Medical Expenditure & $162,500.0 \pm 222,715.6$ & $405,374.1 \pm 913,769.3$ & $<0.001$ \\
Total Annual Expenditure & $578,540.9 \pm 245,977.8$ & $9,675,706.4 \pm 4,449,391.8$ & $<0.001$ \\
\hline
\end{tabular}

Table 4. Illness History

\begin{tabular}{|c|c|c|c|c|c|c|}
\hline \multirow{2}{*}{ Diagnosis } & \multicolumn{2}{|c|}{ Breastfeeding } & \multicolumn{2}{|c|}{ Formula Feeding } & \multicolumn{2}{|c|}{ Total } \\
\hline & n & $\%$ & $\mathbf{n}$ & $\%$ & $\mathbf{n}$ & $\%$ \\
\hline Respiratory Tract Infection & 87 & 48.6 & 92 & 51.4 & 179 & 100.0 \\
\hline Asthma & 1 & 0.1 & 8 & 99.9 & 0 & 100.0 \\
\hline Allergic Symptoms (including diarrhea and vomiting) & 1 & 0.1 & 38 & 99.9 & 39 & 100.0 \\
\hline Measles & 0 & 0.0 & 3 & 100.0 & 3 & 100.0 \\
\hline Dengue Fever & 1 & 0.1 & 7 & 99.9 & 8 & 100.0 \\
\hline Never & 75 & 81.6 & 17 & 18.4 & 92 & 100.0 \\
\hline
\end{tabular}

Table 5. Hospitalization History $(n=165)$

\begin{tabular}{|c|c|c|c|c|c|c|}
\hline \multirow{2}{*}{ Diagnosis } & \multicolumn{2}{|c|}{ Breastfeeding } & \multicolumn{2}{|c|}{ Formula Feeding } & \multicolumn{2}{|c|}{ Total } \\
\hline & $\mathbf{n}$ & $\%$ & $\mathbf{n}$ & $\%$ & $\mathbf{n}$ & $\%$ \\
\hline Allergic Symptoms (including diarrhea and vomiting) & 1 & 5.0 & 19 & 95.0 & 20 & 100.0 \\
\hline Asthma & 1 & 0.0 & 4 & 95.0 & 5 & 100.0 \\
\hline Respiratory Tract Infection & 0 & 0.0 & 5 & 100.0 & 5 & 100.0 \\
\hline Dengue Fever & 1 & 0.0 & 7 & 95.0 & 8 & 100.0 \\
\hline Measles & 0 & 0.0 & 3 & 100.0 & 3 & 100.0 \\
\hline Never & 162 & 57.1 & 127 & 43.9 & 289 & 100.0 \\
\hline
\end{tabular}

For the most expenditure identified in this study, we emphasize on medical related expenses. In formula feeding, most babies experience at least one or two episodes of recurrent illness. The hospitalization is also higher in babies who experience an outpatient report. The occurrence of allergic symptoms and asthma was also found higher in formula feed. Allergic related symptoms were reported high in formula (Comberiati et al., 2019; Mathias et al., 2019; Woicka-Kolejwa et al., 2016).

Allergic symptoms were preserved from the use of feeding equipment, such as pacifier, spoon, and bottled feed. Almost all babies are bottle fed, yet 25\% found irregular pacifier replacement. This compromised hygiene habit using bottle-feed contributes to a reported risk of food allergy. Pacifier and bottle are normally replaced after two or three months' use to minimize the risk of bacteria exposure. Performing disinfection protocol in all feeding equipment is highly recommend for those who have to choose formula milk. The role of midwife and other clinician related to baby and mother care in educating the proper ways of giving formula determines the outcome of healthy feeding behavior in nonbreastmilk baby, especially if the baby is in a condition unable to have breastmilk and direct breastfeeding. 
Substantially reported in developed countries, baby birth is a potential target market for formula milk. The formula industry market estimates that it will reach a sales target of $\$ 70.6$ billion by 2019 (Ezeh et al., 2019; Hemmingway et al., 2020). The production process of consumption of formula milk has been confirmed to have a direct impact on global damage, especially climate change, global warming index, environmental degradation, and pollution (Dadhich et al., 2015). Waste generated from packaging and non-biodegradable plastics accumulates, and is burned in open flames or in incinerators, which results in toxic emissions. Meanwhile, direct breastfeeding can eliminate all negative environmental impacts ( Leissner \& RyanFogarty, 2019). Breastfeeding directly maintains environmental sustainability, is a lifestyle choice with zero waste and zero water footprint (Hamilton, 2015; Linnecar et al., 2014). This study emphasizes the same data, that almost $85 \%$ of families use canned formula milk, the rest use paper boxes. This pack will be added every week. Non-recycled duplication by thousands of families using formula milk adds to the accumulation of solid waste. Meanwhile, waste management technology in Indonesia is still lagging behind, and public awareness of zero waste lifestyle is still low. Milk industry from farming, packaging, storing, distribution, and preparation with a large amount of water aggravate the climate change and water scarcity. Therefore, breastfeeding might the smartest decision in ensuring milk supply chain even in crisis situation (FAO, 2019).

In the economic burden, breastfeeding will save three point six billion, this figure is from preventing premature death of around three point one, and reducing the expenditure of traditional medicine by about 0.5 billion. Traditional medical expenses include hospital visits, laboratory tests, and indirect losses on parental income among those who provide formula milk (Weimer, 2001). In low- and middleincome countries, a lower risk of death in the first year was reported among infants who were breastfed, compared with those who were never breastfed (Black \& Victora, 2002; Kavle et al., 2017; Straub et al., 2019).

Breastfeeding and Obesity: Study links the components of mother's milk to the growth of her baby (Metzger \& McDade, 2010; Papatesta \& Iacovidou, 2013) and shows the accumulative loss seen by families is a ratio of 16-17 times greater than direct breastfeeding. This new ratio is measurable and real, not taking into account long-term ratios such as the resulting productive generation. The WBW 2018 report shows that, by not giving baby milk, there is a loss of 2.6 IQ grade (WHO, 2017). A lower IQ means a lower potential in all possible productivity, including achieving a decent standard of living in the future. Ensuring that the baby is exclusively breastfed for the full term means the assurance of a nutritional basis for growing evenly among others. This option prevents them from malnutrition in any form, including the incidence of expulsive stunting (Child malnutrition). Despite all the benefits of breastfeeding mentioned above, only $40 \%$ of babies each year receive exclusive breastfeeding for up to six months, and $45 \%$ persist for up to two years. Typical failures still revolve around a lack of support from the workplace, community, and health system. Therefore, it takes continuous efforts from all levels to upgrade the scale of the breastfeeding program (Alianmoghaddam et al., 2018; Behzadifar et al., 2019).

\section{CONCLUSION}

This study is empirical evidence of the degree of loss experienced by families by giving formula milk. This tangible loss causes the family to experience economic disabilities in the future. This study has not been able to measure intangible losses, such as the impact of potential IQ loss, and the impact of other non-communicable health disorders such as risk of metabolic syndrome, and obesity. Thus, further researchers can devise strategies to fulfill this aspect, in a higher quality longitudinal study.

\section{REFERENCES}

Abrahams, S. W. (2012). Milk and social media: Online communities and the international code of marketing of breast-milk substitutes. Journal of Human Lactation. https://doi.org/10.1177/0890334412447080

Akman, İ., Kuscu, M. K., Yurdakul, Z., Özdemir, N., Solakoğlu, M., Orhon, L., Karabekiroğlu, A., \& Özek, E. (2008). Breastfeeding duration and postpartum psychological adjustment: Role of maternal attachment styles. Journal of Paediatrics and Child Health, 44(6), 369-373. https://doi.org/10.1111/j.14401754.2008.01336.x

Alianmoghaddam, N., Phibbs, S., \& Benn, C. (2018). Reasons for Stopping Exclusive Breastfeeding Between Three and Six Months: A Qualitative Study. Journal of Pediatric Nursing. https://doi.org/10.1016/j.pedn.2018.01.007

Aubel, J., \& Alvarez, M. (2011). The roles and influence of grandmothers and men: evidence supporting a family-focused approach to optimal infant and young child nutrition: literature review.

Bascom, E. M. E., \& Napolitano, M. A. (2016). Breastfeeding Duration and Primary Reasons for Breastfeeding Cessation among Women with Postpartum Depressive Symptoms. Journal of Human Lactation. https://doi.org/10.1177/0890334415619908

Behzadifar, M., Saki, M., Behzadifar, M., Mardani, M., Yari, F., Ebrahimzadeh, F., Majidi Mehr, H., Abdi Bastami, S., \& Bragazzi, N. L. (2019). Prevalence of exclusive breastfeeding practice in the first six months of life and its determinants in Iran: A systematic review and meta-analysis. In $B M C$ Pediatrics. https://doi.org/10.1186/s12887-0191776-0 
Better Work Indonesia. (2004). Law and Regulations on Breastfeeding.

Black, R. E., \& Victora, C. G. (2002). Optimal duration of exclusive breast feeding in low income countries. In British Medical Journal. https://doi.org/10.1136/bmj.325.7375.1252

Brown, C. R. L., Dodds, L., Legge, A., Bryanton, J., \& Semenic, S. (2014a). Factors influencing the reasons why mothers stop breastfeeding. Canadian Journal of Public Health. https://doi.org/10.17269/cjph.105.4244

Brown, C. R. L., Dodds, L., Legge, A., Bryanton, J., \& Semenic, S. (2014b). Factors influencing the reasons why mothers stop breastfeeding. Canadian Journal of Public Health. https://doi.org/10.17269/cjph.105.4244

Buccini, G. D. S., Beni'cio, M. H. D. A., \& Venancio, S. I. (2014). Determinants of using pacifier and bottle feeding. Revista de Saude Publica. https://doi.org/10.1590/S00348910.2014048005128

Cato, K., Sylvén, S. M., Lindbäck, J., Skalkidou, A., \& Rubertsson, C. (2017). Risk factors for exclusive breastfeeding lasting less than two months Identifying women in need of targeted breastfeeding support. PLOS ONE. https://doi.org/10.1371/journal.pone.0179402

Chowdhury, R., Sinha, B., Sankar, M. J., Taneja, S., Bhandari, N., Rollins, N., Bahl, R., \& Martines, J. (2015). Breastfeeding and Maternal Health Outcomes: A Systematic Review and MetaAnalysis. Acta Paediatrica. https://doi.org/10.1111/apa.13102

Comberiati, P., Costagliola, G., D’Elios, S., \& Peroni, D. (2019). Prevention of food allergy: The significance of early introduction. In Medicina (Lithuania).

https://doi.org/10.3390/medicina55070323

Creedy, D. K., Cantrill, R. M., \& Cooke, M. (2008). Assessing midwives' breastfeeding knowledge: Properties of the Newborn Feeding Ability questionnaire and Breastfeeding Initiation Practices scale. International Breastfeeding Journal. https://doi.org/10.1186/1746-4358-3-7

Dadhich, J., Smith, J., Alessandro, I., \& Adlina, S. (2015). Report on Carbon Footprint Due to Milk Formula: A study from selected countries of the Asia-Pacific region (Issue 10098). https://doi.org/10.13140/RG.2.1.3934.5049

Dennis, C. L., Jackson, K., \& Watson, J. (2014). Interventions for treating painful nipples among breastfeeding women. In Cochrane Database of Systematic Reviews. https://doi.org/10.1002/14651858.CD007366.p ub2

Douglas, P. S., \& Hiscock, H. (2010). The unsettled baby: Crying out for an integrated, multidisciplinary primary care approach. In Medical Journal of Australia. https://doi.org/10.5694/j.13265377.2010.tb04039.x
Eidelman, A. I., \& Schanler, R. J. (2012). Breastfeeding and the Use of Human Milk. PEDIATRICS, 129(3), e827-e841. https://doi.org/10.1542/peds.20113552

Ezeh, O. K., Ogbo, F. A., Stevens, G. J., Tannous, W. K., Uchechukwu, O. L., Ghimire, P. R., \& Agho, K. E. (2019). Factors associated with the early initiation of breastfeeding in economic community of West African States (ECOWAS). Nutrients, 11(11), 1-16. https://doi.org/10.3390/nu11112765

FAO. (2019). The State of Food Security and Nutrition in the World 2019. In The State of Food Security and Nutrition in the World 2019. https://doi.org/10.4060/ca5162en

Gupta, A., Holla, R., Dadhich, J. P., Suri, S., Trejos, M., \& Chanetsa, J. (2013). The status of policy and programmes on infant and young child feeding in 40 countries. Health Policy and Planning. https://doi.org/10.1093/heapol/czs061

Hamilton, A. E. (2015). Development of Environmentally Friendly Messages to Promote Longer Durations of Breastfeeding for Already Breastfeeding Mothers. Health Communication. https://doi.org/10.1080/10410236.2013.84048 3

Hemmingway, A., Fisher, D., Berkery, T., Dempsey, E., Murray, D. M., \& Kiely, M. E. (2020). A detailed exploration of early infant milk feeding in a prospective birth cohort study in Ireland: Combination feeding of breast milk and infant formula and early breast-feeding cessation. British Journal of Nutrition. https://doi.org/10.1017/S0007114520001324

Houghtaling, B., Byker Shanks, C., Ahmed, S., \& Rink, E. (2018). Grandmother and health care professional breastfeeding perspectives provide opportunities for health promotion in an American Indian community. Social Science and Medicine. https://doi.org/10.1016/j.socscimed.2018.05.01 7

Kavle, J. A., Lacroix, E., Dau, H., \& Engmann, C. (2017). Addressing barriers to exclusive breast-feeding in low- and middle-income countries: A systematic review and programmatic implications. In Public Health Nutrition. https://doi.org/10.1017/S1368980017002531

Kent, J. C. (2007). How Breastfeeding Works. Journal of Midwifery and Women's Health. https://doi.org/10.1016/j.jmwh.2007.04.007

Leissner, S., \& Ryan-Fogarty, Y. (2019). Challenges and opportunities for reduction of single use plastics in healthcare: A case study of single use infant formula bottles in two Irish maternity hospitals. Resources, Conservation and Recycling, 151(March), 104462. https://doi.org/10.1016/j.resconrec.2019.10446 2

Linnecar, A., Gupta, A., Dadhich, J., \& Dahiya, A. (2014). Formula Feeding Vs Breastfeeding on Environment.

Mathias, J. G., Zhang, H., Soto-Ramirez, N., \& Karmaus, W. (2019). The association of infant feeding patterns with food allergy symptoms and food 
allergy in early childhood. International Breastfeeding Journal. https://doi.org/10.1186/s13006-019-0241-x

Metzger, M. W., \& McDade, T. W. (2010). Breastfeeding as obesity prevention in the United States: A sibling difference model. American Journal of Human Biology. https://doi.org/10.1002/ajhb.20982

National Population and Family Planning Board (BKKBN), Statistics Indonesia (BPS), Ministry of Health (Kemenkes), and I. I. (2018). Indonesia Demographic Health Survey 2017.

Nicklas, J. M., Miller, L. J., Zera, C. A., Davis, R. B., Levkoff, S. E., \& Seely, E. W. (2013). Factors Associated with Depressive Symptoms in the Early Postpartum Period Among Women with Recent Gestational Diabetes Mellitus. Maternal and Child Health Journal, 17(9), 1665-1672. https://doi.org/10.1007/s10995-012-1180-y

Ogbo, F. A., Eastwood, J., Page, A., Arora, A., McKenzie, A., Jalaludin, B., Tennant, E., Miller, E., Kohlhoff, J., Noble, J., Chaves, K., Jones, J. M., Smoleniec, J., Chay, P., Smith, B., Oei, J. L., Short, K., Collie, L., Kemp, L., ... Kleiman, C. (2017). Prevalence and determinants of cessation of exclusive breastfeeding in the early postnatal period in Sydney, Australia. International Breastfeeding Journal, 12(1), 1-10. https://doi.org/10.1186/s13006-017-0110-4

Olang, B., Heidarzadeh, A., Strandvik, B., \& Yngve, A. (2012). Reasons given by mothers for discontinuing breastfeeding in Iran. International Breastfeeding https://doi.org/10.1186/1746-4358-7-7

Papatesta, E.-M., \& Iacovidou, N. (2013). Breastfeeding reduces the risk of obesity in childhood and adolescence. Journal of Pediatric and Neonatal Individualized Medicine (JPNIM). https://doi.org/10.7363/020206

Phillips-Moore, J. (2012). Birthing outcomes from an Australian HypnoBirthing programme. British Journal of Midwifery, 20(8), 558-564. https://doi.org/10.12968/bjom.2012.20.8.558

Puapornpong, P., Paritakul, P., Suksamarnwong, M., Srisuwan, S., \& Ketsuwan, S. (2017). Nipple Pain Incidence, the Predisposing Factors, the Recovery Period after Care Management, and the Exclusive Breastfeeding Outcome. Breastfeeding Medicine. https://doi.org/10.1089/bfm.2016.0194

Richter, N., \& Reck, C. (2013). Positive maternal interaction behavior moderates the relation between maternal anxiety and infant regulatory problems. Infant Behavior and Development. https://doi.org/10.1016/j.infbeh.2013.04.007
Straub, N., Grunert, P., Northstone, K., \& Emmett, P. (2019). Economic impact of breast-feedingassociated improvements of childhood cognitive development, based on data from the ALSPAC. British Journal of Nutrition. https://doi.org/10.1017/S0007114515001233

Stuebe, A. M., Jegier, B. J., Schwarz, E. B., Green, B. D., Reinhold, A. G., Colaizy, T. T., Bogen, D. L., Schaefer, A. J., Jegier, J. T., Green, N. S., \& Bartick, M. C. (2017). An Online Calculator to Estimate the Impact of Changes in Breastfeeding Rates on Population Health and Costs. Breastfeeding Medicine. https://doi.org/10.1089/bfm.2017.0083

Susiloretni, K. A., Krisnamurni, S., Sunarto, Widiyanto, S. Y. D., Yazid, A., \& Wilopo, S. A. (2013). The effectiveness of multilevel promotion of exclusive breastfeeding in rural Indonesia. American Journal of Health Promotion, 28(2), 1-12. https://doi.org/10.4278/ajhp.120425-QUAN221

Thomas-Jackson, S. C., Bentley, G. E., Keyton, K., Reifman, A., Boylan, M., \& Hart, S. L. (2016). Inhospital Breastfeeding and Intention to Return to Work Influence Mothers' Breastfeeding Intentions. Journal of Human Lactation. https://doi.org/10.1177/0890334415597636

Ulak, M., Chandyo, R. K., Mellander, L., Shrestha, P. S., \& Strand, T. A. (2012). Infant feeding practices in Bhaktapur, Nepal: A cross-sectional, health facility based survey. International Breastfeeding Journal. https://doi.org/10.1186/1746-4358-7-1

Weimer, J. (2001). The Economic Benefits of Breastfeeding: A Review and Analysis. Food Assistance and Nutrition Research Report. https://doi.org/Food Assistance and Nutrition Research Report No. 13.

WHO. (2011). Country Implementation of the International Code of Marketing of Breastmilk Substitutes. WHO STATUS REPORT, 1-62.

WHO. (2017). Nurturing the health and wealth of nations: the investment case for breastfeeding. Unicef, 7.

Woicka-Kolejwa, K., Zaczeniuk, M., Majak, P., Pawłowska-Iwanicka, K., Kopka, M., Stelmach, W., Jerzynska, J., \& Stelmach, I. (2016). Food allergy is associated with recurrent respiratory tract infections during childhood. Postepy Dermatologii $i$ https://doi.org/10.5114/ada.2016.59151

Xu, F., Li, Z., Binns, C., Bonello, M., Austin, M.-P., \& Sullivan, E. (2014). Does infant feeding method impact on maternal mental health? Breastfeeding Medicine: The Official Journal of the Academy of Breastfeeding Medicine. https://doi.org/10.1089/bfm.2013.0142 